\title{
A STUDY OF CLOSED INTERLOCKING NAILING FOR FRACTURES OF SHAFT OF FEMUR IN ADULTS
}

Ashwin Kasturi' ${ }^{1}$, Srinivasan. N², B. Arvind ${ }^{3}$, M. Kiran ${ }^{4}$, E. Veeraji ${ }^{5}$.

1. Assistant Professor, Department Of Orthopaedics, Malla Reddy Institute of Medical Science

2. Professor, Department Of Orthopaedics, Malla Reddy Institute of Medical Science

3. Assistant Professor, Department Of Orthopaedics, Malla Reddy Institute of Medical Science

4. Assistant Professor, Department Of Orthopaedics, Malla Reddy Institute of Medical Science

5. Senior Resident, Department Of Orthopaedics, Malla Reddy Institute of Medical Science

\section{CORRESPONDING AUTHOR:}

Dr. Ashwin Kasturi,

Plot no:524, Bhagath Singh Nagar,

Near JNTU, KPHB Colony, Hyderabad.

E-mail:ashwinkasturi@gmail.com

\section{HOW TO CITE THIS ARTICLE:}

Ashwin Kasturi, Srinivasan. N, B. Arvind, M. Kiran, E. Veeraji. "A study of closed interlocking nailing for fractures of shaft of femur in adults". Journal of Evolution of Medical and Dental Sciences 2013; Vol2, Issue 24, June 17; Page: 4469-4480.

\begin{abstract}
:
BACKGROUND:-This study is to determine the clinical course and results after interlocking nailing for femoral shaft fractures, merits and demerits of interlocking nailing, achieving the final goals of femoral shaft fracture management with special references to time for radiological union, knee stiffness, limb length discrepancy, ambulation and return to work.

Femur is the strongest and heaviest bone in the human skeleton. It is also the longest bone contributing $26 \%$ to height of an individual. Fractures of the shaft of the femur are among the most common fractures encountered in orthopaedic practice, can cause prolong morbidity and extensive disability unless treatment is appropriate. Many treatment modalities were described; with many surgeons advocating different methods of treatment .At present Interlocking nailing of the femur seems to be the ideal method of treatment for complex femoral fractures.
\end{abstract}

STUDY DESIGN: This is a 'Descriptive Study' where Patients attending Outpatient Department of Orthopaedics \& Emergency Care Department, Malla Reddy Hospital/MRIMS, Hyderabad during the study period i.e; December $1^{\text {st }} 2011$ to August $31^{\text {st }} 2012$ were screened and a group of 40 patients with unilateral femoral shaft fracture (Closed fractures and Gustilo type I compound fractures) within an age group between 18-80 years were selected. Patients of age less than 18 years and greater than 80 years are excluded. Patients with Gustilo Type II and Type III compound fractures, associated with Ipsilateral fracture neck and/or distal femur, bilateral fracture shaft femur are excluded.

For the selected group closed Interlocking nailing done on fracture table under C-ARM guidance under Regional/ General Anesthesia. Initial non-weight bearing advised. Patients were followed up 


\section{ORIGINAL ARTICLE}

at regular intervals for some patients' upto 32 weeks. Subsequent weight bearing done as union progressed.

RESULTS: The average time to union was 18 weeks ranging from 14 to 32 weeks. Wiss et al; ${ }^{1}$, obtained union at an average of 26 weeks with $1.8 \%$ non union. We have found no two studies using the same criteria for assessing their results. We have modified Thoresen ${ }^{2}$ et al. criteria and made it more stringent. Thoresen ${ }^{2}$ criteria states that $5^{\circ}$ of varus, valgus, external or internal rotation or recurvatum were considered as excellent results. In our study excellent result required absolute anatomic alignment. Hence comparison would not hold good. Klemm and Borner ${ }^{3}$ have had their criteria, which come closer to our criteria. Criteria included pain, deformity, limb length discrepancy, infection, ROM hip and knee. We had 60\% excellent, 30\% good and 5\% fair and 5\% poor results.

CONCLUSIONS: The findings in our study suggested that Interlocking nailing allowed early protected weight bearing, and joint movement .It has decreased the mortality and dependency of the patient. The rates of infection and non-union or mal-alignment are low .Interlocking intramedullary nailing has proved to be an excellent mode of treatment for complex, comminuted, segmental and unstable femoral fractures. Since the closed intramedullary nailing does not disturb the fracture haematoma, aiding in better healing. Good range of motion is achieved, as the fibrosis due to muscle dissection which is inevitable in open nailing, is avoided by closed nailing. Static nailing with interlocking nailing with interlocking screws both above and below the fracture site secures the best stability of the fracture. Dynamic nailing with interlocking screws only through one of the ends of the nail allows the fracture site to be compressed during early weight bearing and helps in early healing of the fracture. Interlocking has a definite place in the management of Grade-I open fractures. (Delayed, unreamed nailing is preferred.) Fractures of the shaft of the femur associated with metaphyseal fractures, intercondylar fractures, intracapsular fractures can ideally be treated by specially designed interlocking nails, like Recon Nail, Gamma Nail and far distal holed nails.

KEY WORDS: Fracture, Femur, Interlocking nail, Union.

INTRODUCTION: Femur is the strongest and heaviest bone in the human skeleton. It is also the longest bone contributing $26 \%$ to height of an individual. Even in a closed fracture one to one and a half liters of blood is lost into tissues. Femur is essential for weight bearing and also for movement as it takes part in the formation of knee and hip joints.

Conservative treatment methods like skeletal traction, Thomas ${ }^{4}$ splinting and P.O.P. spica cast, resulted in $30 \%$ complications like pin track infection, shortening, mal-alignment and nonunion. Anatomical alignment can be achieved by plate fixation, but there are complications like delayed union and fatigue fracture of the metal.

In 1990, Kuntscher ${ }^{5}$ to meet the emergent situation practiced closed I.M. nailing as advocated by Lambrinudi ${ }^{6}$, with good results. Very soon, this method of ante-grade insertion and also retrograde insertion after open reduction became popular in U.K. and America.

Perfect form of therapy of femoral shaft fracture is one in which fracture is firmly fixed, so that soft tissue structures and adjacent joints may be mobilized early and continuously, while the fracture is uniting safely, thus permitting ambulation with early weight bearing. However, in a 
majority of shaft fractures a near approach to such a perfect therapy may be found in medullary fixation with an interlocked intramedullary nail.

With recent epidemic of high velocity trauma, the number of multi-system injured patients with complex femoral fractures has increased. Many treatment modalities were described, with many surgeons advocating different methods of treatment. At present Interlocking nailing of the femur seems to be the ideal method of treatment for complex femoral fractures.

MATERIALS \& METHODS: This is a descriptive study conducted in Department of Orthopaedics, Malla Reddy Hospital/MRIMS, Hyderabad. From December $1^{\text {st }} 2011$ to August 31 $1^{\text {st }} 2012.40$ patients with femoral shaft fractures were selected among the patients attending Outpatient Department of Orthopaedics \& Emergency Care Department, Malla Reddy Hospital/MRIMS, Hyderabad during the study period, closed interlocking nailing done, with inclusion and exclusion criteria as stated below

Inclusion Criteria: a) Age group between 18-80 years with fracture shaft of femur, b) Closed fractures and Gustilo type I compound fractures.

Exclusion Criteria: a) Age less than 18 years and greater than 80 years, b) Gustilo Type II and Type III compound fractures, c) Associated with Ipsilateral fracture neck of femur, intra-articular distal femur fractures and bilateral femur fractures.

In our study which was conducted over 40 femoral shaft fractures. Of the 40 patients 36 (90\%) had R.T.A, 4 (10\%) had fall. As per A.O. classification of diaphyseal fractures there were as follows: 8 spiral, 6 oblique, 16 transverse, 6 spiral wedge and 4 bending wedge. As per Winquist and Hansen ${ }^{7}$ classification for comminution there were 18(45\%) no comminution, 10 (25\%) Type I (insignificant butterfly fragment), 8 (20\%) Type II (large butterfly fragment $<50 \%$ cortical contact) and $4(10 \%)$ were of Type III (large butterfly fragment $>50 \%$ cortical contact).

Out of the total patients six had ipsilateral tibia/fibular fractures, three had contralateral tibia/fibular, one had pelvi-acetabular injury, two had head injury, three had oromaxillo-facial injury, and three had multiple rib fractures.

Initial X-rays were taken and classified by A.O. and Winquist and Hansen ${ }^{7}$ classification. Patients were immobilized in a Thomas ${ }^{4}$ splint and then the patients were stabilized. Pre-operatively skeletal tractions were applied in few patients to keep the fracture fragments slightly distracted. The measurement of the length of the nail was taken pre-operatively from the tip of the greater trochanter to the superior pole of the patella of contra lateral femur. We did not include patients with bilateral femur fracture, for discussion in such cases the length from tip of olecranon process to the tip of little finger, or $25 \%$ of height of the individual are accounted for the femoral shaft length.

PROCEDURE: Either regional or general anesthesia was given depending upon the general condition (co-morbidity, poly trauma).

I. M. Nailing was performed with the patient on a fracture table in a supine position. Supine position is more physiological for multiple injured patients. 
Correct starting position is directly in line with medullary cavity of shaft as identified. The point is just medial to the most prominent part of trochanter, and slightly posterior to it. The fascia lata and the fibres of gluteus maximus are divided in line with the skin incision. Rotation of the bent tip of guide is useful when passing the guide wire across the fracture site.

Reaming the canal sequentially at $0.5 \mathrm{~mm}$ intervals until the reaming exceeds the selected nail diameter by $1.0 \mathrm{~mm}$ does canal preparation.

Usually I.M nailing, of diameter of 11 to $12 \mathrm{~mm}$ is suitable. In elderly patients and in nonunion, larger diameter is needed. After application of proximal targeting device, nail is inserted into I.M. canal over $4 \mathrm{~mm}$ nail driving guide. After the nail is passed through fracture site traction is released and fracture is impacted.

Once nail and fracture reduction is verified under image intensifier, locking bolts are inserted after guide wire is withdrawn. Proximal bolts are inserted first. Sometimes distal locking bolts are inserted first in order to impact the fracture site first and to back the nail out slightly at proximal end. Some manufacturers recommended insertion of an end cap to prevent bone growth and to facilitate nail removal later.

Distal Locking: We have used 'free hand method' technique. Image intensifier is positioned perpendicular to the distal femur by abducting the hip if the patient is supine. Perfectly round holes must be identified on the monitor if image intensifier parallel to the coronal plane of femur. A dent is made by awl in the middle of hole identified by image intensifier beam on lateral cortex. This dent is necessary to prevent drill bit wandering on smooth lateral cortex. This awl is then exchanged for drill bit. Under image intensifier control drill bit is advanced through the hole of nail and medial cortex and then locking screw is inserted. In obese patients, the two stab incisions, needed for two holes, are connected for better retraction of soft tissues

A suction drain is left, before closing the incised wound and, A.P. view X-ray (image intensifier) in internal rotation of hip is taken to make sure that an iatrogenic femoral neck fracture is not present. Knee stability is assessed before anaesthesia is discontinued.

FOLLOW UP: These patients were regularly called in for follow up after discharge from hospital after (POD) post operative day 4 to 7 . Called for suture removal on POD 11 to 13 and then after 2 weeks i.e; around 1 month where in clinical and radiographic assessment done , there after assessment done every month till union. Few were called in between months based on clinical and radiological assessment.

WEIGHT BEARING: Touch-down (non weight) weight bearing is allowed on the first postoperative day, and hip and knee range of motion is encouraged. Quadriceps-setting and straight leg raising exercises are begun before hospital discharge. Hip abduction exercises are begun after wound healing. Weight bearing is progressed as callus formation occurs. Non weight bearing for was advised for initial 4 to 6 wks for majority of patients, extending upto 10 weeks for few of the patients. After that partial weight bearing advised till union has occurred and then full weight bearing advised. In our study full weight bearing given at 14 weeks for $4(10 \%)$ patients, at 16 weeks for $12(30 \%)$, at 18 weeks for $17(42.5 \%)$, at 20 weeks for $5 \&$ at 22 weeks for 1 patient.

OBSERVATIONS: The average age of the patients in our series was 45 years with a range of 18 to 80 years. There were 34 males against 6 females, of which 28 cases were right sided and 12 were 
left sided fractures shaft of femur. Thirty six patients had a history of road traffic accident; four patients had a fall from height. The average duration of surgery was 2 hours (120 min) with a range of 90 to 150 minutes. Union of fractures in closed nailing occurred in 18 weeks in our study. The criteria was presence of external bridging callus, and callus should have the same density as the cortex.

DISCUSSION: Interlocking nail has revolutionized the management of femoral shaft fractures. In our study, 40 cases of femoral shaft fractures were treated with interlocking nailing. The average age of the patients in our series was 45 years with a range of $18-80$ years. The average in Wiss et al ${ }^{1}$, series was 28 years with a range of 15 - 87 years, Johnson and Greenberg 8, 25 years with range of 16 - 75 years and Brumback et al ${ }^{9}$ reported a range of $14-73$ years with average of 29 years. Sex incidence-Male constituted 85\% (34) while female patients were 15\%(6) in our study. The other studies reported were Wiss et al ${ }^{1}$ - males $83.78 \%$ and females $16.22 \%$, Thoresen et al ${ }^{2}$ males $48.94 \%$ and females $51.06 \%$, Johnson and Greenberg ${ }^{8}$ males $79.89 \%$ and females $18.44 \%$ and Brumback et al ${ }^{9}$ reported males $17.86 \%$ and females $20.24 \%$. The variations in age and sex can be explained on the different socioeconomic profiles of the compared series. Side involved: Right sided fractures were $70 \%$ and left sided in 30\% which compares well with Johnson and Greenberg ${ }^{8}$ - right $62.09 \%$ and left 38\%, Brumback et al: ${ }^{9}$ reported $45.24 \%$ in right and $54.76 \%$ in left, Wiss et al ${ }^{1}$ - right $52.15 \%$ and left $47.75 \%$.

Mode of injuries: Road traffic accident with high velocity trauma caused injuries in $90 \%$ and low velocity injuries like fall caused $10 \%$ of injuries in our study which is similar to the study of Johnson and Greenberg8 reported $87 \%$ to road traffic accident and 7\% to fall, the rest to gunshot injuries as in the study of Wiss et al ${ }^{1}$; Thoresen et al: ${ }^{2}$ has high velocity injury inclusive of road traffic accident $65.96 \%$ and low velocity trauma in $34.04 \%$ Wiss et al: ${ }^{1}$ - road traffic accident $8.5 \%$ and fall $16.22 \%$.

Associated injuries: Associated injuries in our study were seen in $76.47 \%$ of patients reflecting the relatively higher percentage of high velocity trauma when compared to those of Wiss et al ${ }^{1} 58 \%$, Thoresen et al; $243.43 \%$ and 53\% in the study of Johnson and Greenberg ${ }^{8}$.Type of fracture: In our study we have selected closed fractures and Gustilo type I compound fracture. Closed fractures were $72.5 \%$ and Gustilo type I compound fractures were $27.5 \%$ in our study. Type of fracture based on AO classification represented in table (2). Other studies Viz, Thoresen et al; ${ }^{2}$ closed fractures $87.5 \%$ and open fractures $12.5 \%$, Johnson and Greenberg ${ }^{8}$ closed fractures $72 \%$ and open fractures $27.93 \%$, Brumback et $\mathrm{al}^{9}$; open fractures $23.8 \%$ and closed fractures $76.2 \%$,Christie et al; ${ }^{10}$ reported $16.17 \%$ open fractures and (Type I-6.8\%, Type-II-3.34\% and Type - III - 6.03\% ).In our study 55\%, the fractures were comminuted (Type I- 25\%, Type -II - 20\%, Type III -10\% and type- IV- $0 \%$. Studies of Wiss et al; ${ }^{1}$ had $76.75 \%$ comminuted fractures .

Interval between nailing and injury: The average interval between injury and nailing was 7 days ranging between 1 to 13 days, to compare from those of Wiss et al; ${ }^{-1} 10$ days for closed and 17 days for open fracture, Thoresen et al;2- $83.34 \%$ within 14 days and $16.8 \%$ within 2 to 3 weeks, however most other authors like Johnson and Greenberg8 operated within 2 days and Brumback et $\mathrm{al}^{9}{ }^{9}-83.34 \%$ within 1 day and $16.8 \%$ with an average of 10 days. In our study $67.5 \%$ underwent nailing within 4-6 days while $32.5 \%$ at an average of 10 days which compares well with the above studies with respect to closed fractures. 
Duration of surgery: The average duration of surgery was 2 hours with a range of $1.5-2.5$ hours which compares with the study of Wiss et al; ${ }^{1}$ with 3.15 hours for static nailing. However Thoresen et $\mathrm{al}^{2}$ operated within 1.5 hours ranging between 45 to 118 minutes and Johnson and Greenberg8,2 hours to 2.40 hours.

REDUCTION: Closed reduction was attempted in all fractures by manual traction and manipulation under image intensifier control. Closed reduction was difficult or could not be achieved in those patients in whom the interval between injury and surgery was more and in those whom preoperatively heavy traction was not applied or delayed surgery for various reasons such cases were not included in our study.

Mode of locking: Dynamic mode of locking was used in 10 patients (25\%), and in 30 patients (75\%) static locking was done in our study. Thoresen et al; ${ }^{2}$ in the earliest study had static locking in $27 \%$ and $73 \%$ in dynamic mode, Wiss et al; ${ }^{1}$ later had $73 \%$ static locking and $27 \%$ dynamic locking based on Winquest and Hansen's ${ }^{7}$ classification of comminution. However $10 \%$ loss of reduction and shortening seen in Brumback et al; ${ }^{9}$ previous study led to $100 \%$ static locking in his later study.

Duration of C-arm use: The average duration of $C$ Arm use in our study was 4 minutes ranging from 2 to 6 minutes. Grosse et al reported a mean of 2.8 minutes of irradiation time. Jaswinder Grover $^{11}$, Donald A and Wiss reported that the average time of radiation emittance for insertion of nail and proximal locking screw was $1.44-2.48$ minutes.

Post operative complications: Acute superficial infection was seen in one case of closed nailing, $(2.5 \%)$ in our study, which was debrided and irrigated, and the wound healed with secondary intention. One patient(2.5.\%) with head injury who had developed superficial infection and also bore weight at two weeks against advice and had minimal bending but led to uneventful union. Two patients (5\%) had distal screw irritation which were removed after 16 weeks . Two patient(5\%) had wasting of thigh of $2 \mathrm{cms}$. At the time of evaluation three patients (7.5\%) complained of sporadic significant pain in the thigh. Mal alignment in varus of $5-10^{\circ}$ was noticed in three patients i.e one of them had $10^{\circ}$ of varus following closed nailing in the secondary deformed femur leading to mismatch in the curvature of the nail and femur, and hence the varus position.

Valgus alignment was noted in two patients one of them had a $10^{\circ}$ valgus union with a type III comminution locked in a dynamic mode due to the difficulty of proximal locking secondary to hardware problems. There were no cases of lengthening or internal rotation deformity, probably because we have used the supine position and traction on fracture table.

FUNCTIONAL ASSESMENT: The function of the knee and the hip in nearly $80 \%$ has been excellent to good (68\% full range and $12 \%$ more than $100^{\circ}$ of flexion of the knee). Wiss et al; ${ }^{1}$ had superficial infection in $0.9 \%$, change on length in $15 \%, 11.5 \%$ lengthening and $3.5 \%$ shortening. In our study one developed shortening after dynamization, one due to failed attempt at static locking following problem with image intensifier, some of the patients had residual angulation $(12.5 \%)$, varus (7.5\%) and valgus ( $5 \%$ ) with 1 case of nail bending with $15^{\circ}$ varus angulation, $12.5 \%$ patients had (more than $5^{\circ}$ ) anterior $5 \%$ and $7.5 \%$ posterior angulation $\left(5-20^{\circ}\right) .7 .5 \%$ had external rotation deformity between $10-30^{\circ}$. Non union was noticed in $2.5 \%$ with no indication of deep infection or osteomyelitis, knee flexion of $90^{\circ}$ was found in $2.5 \%$. Thoresen, et al; ${ }^{2}$ had malalignment of $6.25 \%$ in varus $2 \%$ in valgus, $2 \%$ in internal rotation, $4 \%$ in external rotation and $4 \%$ with recurvatum 
deformity. Pain was complained and $4 \%$ had knee extension deficit in $4 \%$ knee flexion $>100^{\circ}, 2 \%>$ $90^{\circ}$ but $<120^{\circ}$ and $100^{\circ}$ knee flexion respectively. Christie, et al; ${ }^{10}$ reported superficial infection in $0.8 \%$ non union in $1-6 \%$, lateral rotation in $0.8 \%$, and delayed union in $1.6 \%$.

CONCLUSIONS: At the end of our study we came up with the following conclusions:

The findings in study suggested that Interlocking nailing allowed early protected weight bearing, and joint movement .It has decreased the mortality and dependency of the patient. The rates of infection and non-union or mal-alignment are low.

The union rates are comparable in dynamic and the static locking, in relation to level of fractures, open and closed nailing, laterality and degree of comminution. The interlocking nail has widened the range of indications for medullary osteosynthesis of femoral shaft fractures. Interlocking intramedullary nailing has proved to be an excellent mode of treatment for complex, comminuted, segmental and unstable femoral fractures, especially in the multiple injured patients.

Since the closed intramedullary nailing does not disturb the fracture haematoma, aiding in better healing. Since, the fracture site is not opened the chances of post operative infection of fractures site is removed. Good range of motion is achieved, as the fibrosis due to muscle dissection which is inevitable in open nailing, is avoided in closed nailing.

Static nailing with interlocking nailing with interlocking screws both above and below the fracture site secures the best stability of the fracture. Dynamic nailing with interlocking screws only through one of the ends of the nail allows the fracture site to be compressed during early weight bearing and helps in early healing of the fracture.

Interlocking has a definite place in the management of Grade-I open fractures.

MODIFIED THORESEN ${ }^{2}$ et al. CRITERIA represented in table (1).

Overall functional grading in my series represented in table (2).

\section{BIBLIOGRAPHY:}

1. WISS. D.A, CHRISTOPHER H. FLEMING. JOEL M. MATTA, AND COUGLAS CLARK, Comminuted and Rotationally Unstable Fractures of the Femur Treated with an Interlocking Nail, Clin Orthop Relat Res 212; 35-47, 1986.

2. THORESEN.B.O., ANTTIALHO, ARNE EKELAND, KNUT STROMSDE, GUNNAR FOLLERAS AND ARNE HAUKEBO, Interlocking Intramedullary Nailing in Femoral Shaft Fractures : J. bone and Joint Surg., 8-A:1313-1320, P.C. 1985.

3. KLEMM. K. W, AND MARTIN BORNER,: Interlocking Nail of Complex Fractures of the Femur and Tibia. : Clin. Ortho. 212:89-100, 1986.

4. THOMAS. H. O: The Treatment of Deformation, Fractures and Diseases of Bones in the Lower Extremities. LONDON. H. K. Lewis, 1890.

5. KUNTSCHER G, The intramedullary nailing of fractures. Clin Orthop ; 60:5-12,1968.

6. LAMBRINUDI, C.; Intramedullary Kirscher wires in the treatment of fractures. Proc. Roy. Soc. Med. 33:153, 1940.

7. WINQUEST and HANSEN'S classification; ROCKWOOD, CHARLES.A, GREEN, DAVID. P AND BUCHOLZ, ROBERT W: Fractures in Adults, Philadelphia: J. B. Lippincott Company, $6^{\text {th }}$ Edition, Pg-1850.

8. JOHNSON, K.D. AND MARK GREEN BERG: C Comminuted femoral shaft fractures,: Ortho. Clin. North America, 18: 133 - 147, 1987. 


\section{ORIGINAL ARTICLE}

9. BRUMBACK. R. J, J. DENISE WELLS, RONALD LACATOS, ATTILA POKA, G. HOWARD BATHON and ANDREW R. BURGESS, Intramedullary Nailing of Femoral shaft Fractures: J. Bone Joint Surg., 74-A: 106-112, Jan. 1992.

10. CHRISTIE .J, C. COURT-BROWN, A.W.G. KINNINMONTH C.R. HOWIE, : Intramedullary locking Nails In The Management of Femoral Shaft Fractures : J. Bone and Joint Surg., 70-B : 206-210, March 1988.

11. GROVER. J and DONALD A. WISS, A Prospective Study of Fractures of the Femoral Shaft Treated with a Static, Intramedullary, Interlocking nail comparing one Versus two distal screws; Ortho.clin.North America, 26:139-146, 1995.

TABLE: 1 MODIFIED THORESEN² et al. CRITERIA

The following was used to grade the result.

1 PAIN

\begin{tabular}{|l|c|}
\hline No Pain & 4 \\
\hline Mild Pain (Pain occasionally on prolonged strain) & 3 \\
\hline Moderate Pain (has to change over to light duties) & 2 \\
\hline Severe Pain (restricting routine activities) & 1 \\
\hline
\end{tabular}

2 DEFORMITY

\begin{tabular}{|l|c|}
\hline No deformity (either rotational or angulatory). & 4 \\
\hline Mild deformity (rotation or angulation less than 10 degrees). & 3 \\
\hline Moderate deformity (rotation or angulation of 10 to 20 degrees & 2 \\
\hline Severe deformity (rotation or angulation more than 20 degrees & 1 \\
\hline
\end{tabular}

3. LIMB LENGTH DISCREPANCY :

\begin{tabular}{|l|c|}
\hline No discrepancy & 4 \\
\hline Minimal shortening $(1.2 \mathrm{~cm})$ & 3 \\
\hline Moderate shortening $(2-3 \mathrm{~cm})$ & 2 \\
\hline Shortening more than $3 \mathrm{~cm}$ & 1 \\
\hline
\end{tabular}




\section{ORIGINAL ARTICLE}

4 RANGE OF MOVEMENT OF HIP AND KNEE

\begin{tabular}{|l|c|}
\hline No restriction & 4 \\
\hline Terminal restriction of movement (hip flexion upto110,knee upto130degrees) & 3 \\
\hline Moderate restriction of movement (hip upto 90 ,knee upto 100 degrees) & 2 \\
\hline $\begin{array}{l}\text { Gross restriction } \\
\text { (hip }<90, \text { knee }<100 \text { degrees) }\end{array}$ & 1 \\
\hline
\end{tabular}

5 INFECTION

\begin{tabular}{|l|l|}
\hline No infection & 4 \\
\hline Infected & 1 \\
\hline
\end{tabular}

The results were graded as

\begin{tabular}{|l|l|}
\hline $16-20$ & Excellent \\
\hline $11-15$ & Good \\
\hline $6-10$ & Fair \\
\hline $1-5$ & Poor \\
\hline
\end{tabular}

TABLE: 2 Overall functional result in my series:

\begin{tabular}{|l|l|}
\hline Functional grading & No. of cases \\
\hline Excellent & $24(60 \%)$ \\
\hline Good & $12(30 \%)$ \\
\hline Fair & $2(5 \%)$ \\
\hline Poor & $2(5 \%)$ \\
\hline
\end{tabular}




\section{ORIGINAL ARTICLE}

\section{Surgical Procedure}

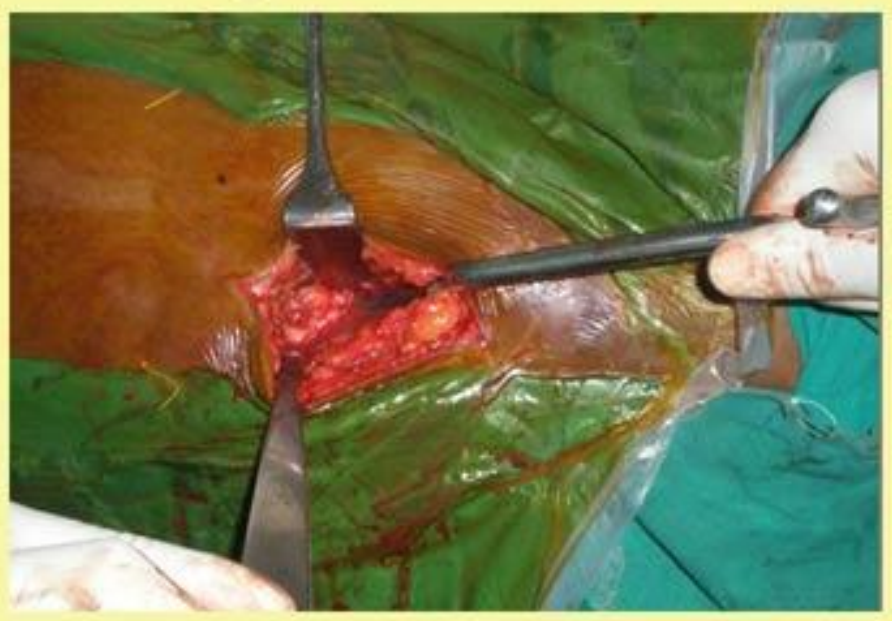

Confirmation of Trochanter \& Portal Entry in Pyriformis Fossa

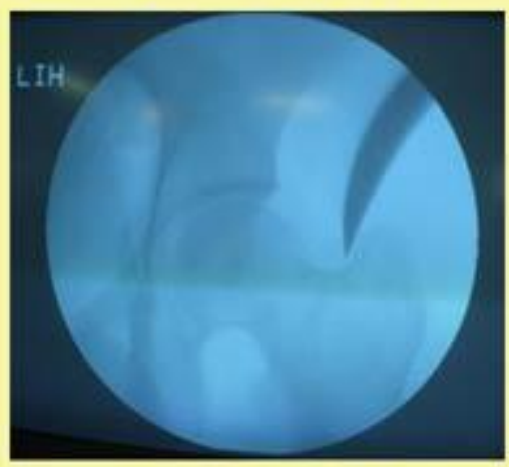




\section{ORIGINAL ARTICLE}

\section{Surgical Procedure}
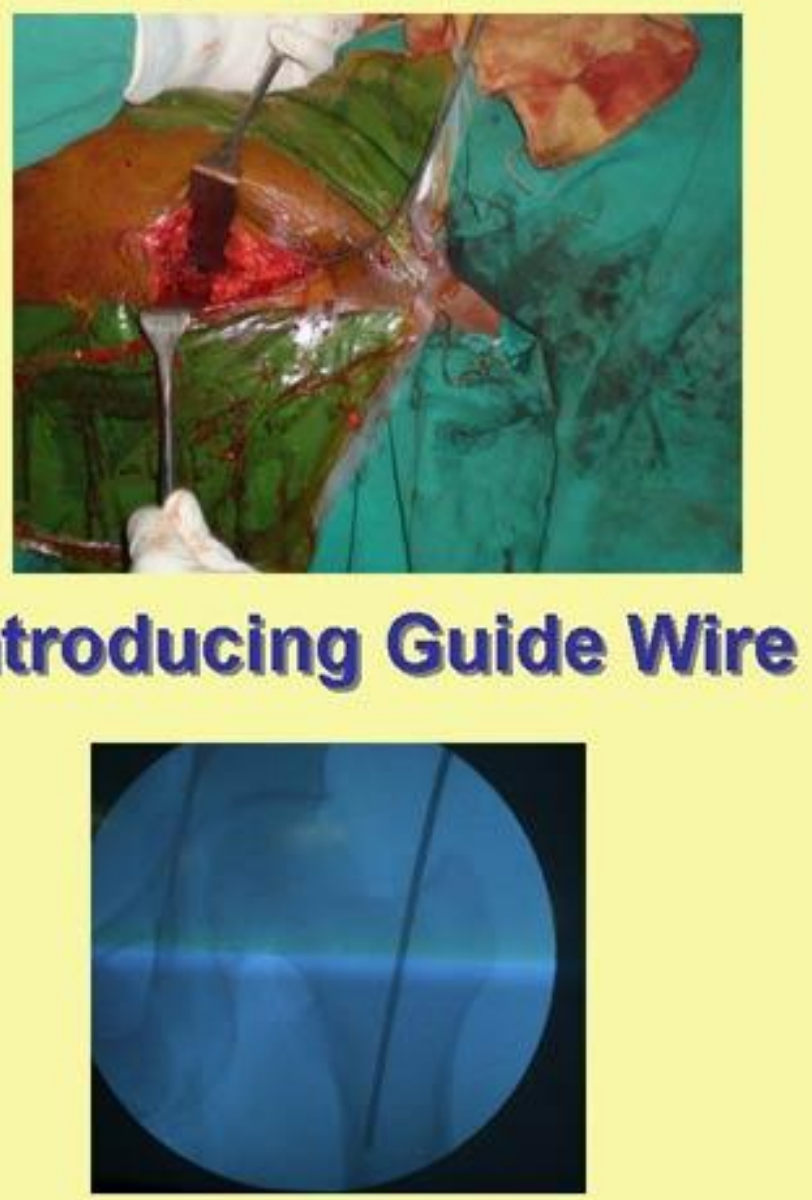


\section{ORIGINAL ARTICLE}

\section{Surgical Procedure}

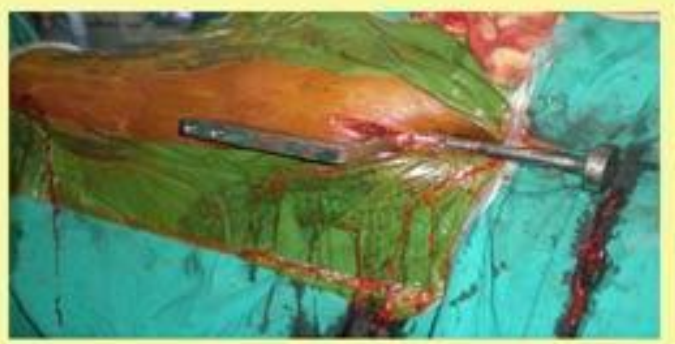

Nail passed in to I.M. Canal, Proximal jig in Position

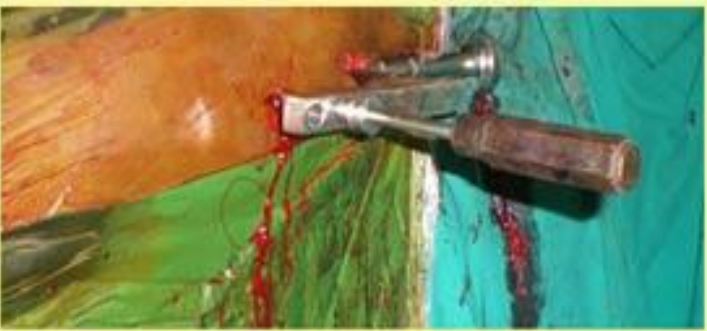

Proximal Interlocking (with jig)

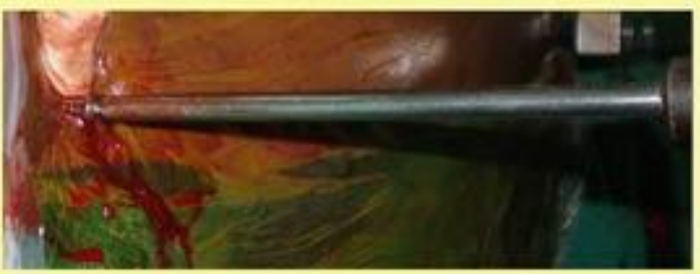

Distal Interlocking (Free hand technique) 